\title{
Cerambycidae (Insecta, Coleoptera) Associados à Vochysia divergens Pohl (Vochysiaceae) na Região Norte do Pantanal de Mato Grosso, Brasil
}

\author{
Marinêz Isaac Marques, Geane Brizzola dos Santos \& Leandro Dênis Battirola
}

1. Universidade Federal de Mato Grosso, e-mail: marinez513@gmail.com, ldbattirola@uol.com.br (Autor para correspondência ${ }^{\bowtie}$ ), gbrizola@yahoo.com.br.

\section{EntomoBrasilis 7 (2): 159-16o (2014)}

Resumo. Este estudo registra da associação entre três espécies de Cerambycidae e Vochysia divergens Pohl (Vochysiaceae), espécie vegetal típica da região norte do Pantanal de Mato Grosso, que além de formar adensamentos monodominantes é considerada uma invasora de campos e pastagens nativas nesta região. Neste estudo, galhos e troncos desta espécie vegetal foram coletados ao longo de um ano (julho/1999 a junho/200o) e monitorados em laboratório para avaliação da densidade e período de emergência dos cerambicídeos. Como resultado foram amostrados 277 indivíduos representando as espécies, Psapharochrus bivittis (White), Luscosmodicum beaveari Martins e Neoeme bouvieri Gounelle. Além do registro da associação, observou-se que o pico de emergência dos Cerambycidae coincide com o início do período de enchente e cheia na região norte do Pantanal, evidenciando o sincronismo entre o desenvolvimento biológico destas espécies e o ciclo hidrológico desta região.

Palavras-chave: Áreas inundáveis; Coleópteros xilófagos; Interação.

\section{Cerambycidae (Insecta, Coleoptera) Associated with Vochysia divergens Pohl (Vochysiaceae) in the Northern Region of the Pantanal of Mato Grosso, Brazil}

Abstract. This study aims the registration of the association between Cerambycidae and Vochysia divergens Pohl (Vochysiaceae), typical plant species of the northern region of the Pantanal of Mato Grosso that besides forming monodominant stands and is considered a weed of fields and pastures in this region. In this study, branches and trunks of this specie were collected over one year (July/1999 - June/2000) and lab monitored for density and emergency time evaluation of Cerambycidae. As results 277 individuals were sampled, representing the species, Psapharochrus bivittis (White), Luscosmodicum beaveari Martins and Neoeme bouvieri Gounelle. In addition to registration of the association, it was noted that the emergence peak of Cerambycidae coincides with the beginning of flood and high water period in northern Pantanal, showing the synchronization between the biological development of this species and the hydrological cycle in this region.

Keywords: Interaction; Xylophages Coleoptera; Wetlands.

V ochysia divergens Pohl (Vochysiaceae) é uma espécie arbórea considerada colonizadora dos campos inundáveis do Pantanal de Mato Grosso. Nesta região, esta espécie forma adensamentos monodominantes, denominados cambarazais, sendo que seu processo de formação parece ser contínuo, avançando sobre áreas de pastagens naturais e introduzidas, tornando-se um dos piores problemas para a população local, devido à redução de áreas úteis para a pecuária (NASCimento \& NunEs DA CunHA 1989).

Apesar de constituir um problema para a pecuária na região, estudos abordando sua interação com a fauna demonstraram que $V$. divergens é fundamental para a manutenção da diversidade biológica do Pantanal, principalmente, com relação aos Coleoptera (MARQues et al. 2001, 2006). Embora a associação entre cerambicídeos e espécies de Vochysia tenha sido registrada (Martins 1997; Martins \& Galileo 2004), estudos sobre biologia e ecologia desse grupo são escassos. Os Cerambycidae constituem um grupo importante sob o ponto de vista florestal e agrícola, já que suas larvas são xilófagas e broqueiam os troncos e galhos podendo causar prejuízos econômicos (MARTins 1997) além de atuarem na biodeterioração destes substratos (e. g. ABREu et al. 2009). Considerando a importância desta espécie vegetal na composição de uma das principais fitofisionomias florestais do da região norte do Pantanal, este trabalho apresenta registros de associação entre três espécies de Cerambycidae e $V$. divergens.
As coletas foram realizadas entre julho/1999 ejunho/2000 em um cambarazal, floresta monodominante sazonalmente inundável, no Pantanal de Cuiabá - Bento Gomes - Paraguaizinho, denominado Pantanal de Poconé, no distrito de Pirizal, Fazenda Retiro Novo $\left(16^{\circ} 15^{\prime} 12\right.$ "S e $56^{\circ} 22$ ' 12 "W), município de Nossa Senhora do Livramento, Mato Grosso. Foram realizadas coletas bimensais de troncos e galhos caídos no solo, por quatro coletores durante seis horas (6 horas/coletor/dia), totalizando 192 horas/ coletor durante todo o período amostral. Todos os troncos e galhos cortados de $V$. divergens, com sinais de ataque de Cerambycidae foram coletados e armazenados em sacos de ráfia, transportados para o Laboratório de Ecologia e Taxonomia de Artrópodes (LETA) do Instituto de Biociências da Universidade Federal de Mato Grosso, e acondicionados em caixas de madeira teladas para monitoramento deste material.

Ao longo do monitoramento os galhos e troncos foram umedecidos cerca de três vezes por semana, e durante este procedimento os adultos de Cerambycidae que eventualmente eclodiram eram coletados e acondicionados para a devida montagem e etiquetagem. Concomitantemente ao início das chuvas na região norte do Pantanal, no mês de outubro, os troncos e galhos foram transportados para caixas de amianto de 1.000 $\mathrm{L}$, onde foram realizadas simulações de enchente, tendo como base as informações oriundas da área de estudo, para manter as condições similares as existentes em campo. Os adultos após 
T emergência eram recolhidos em tubos mortíferos, montados e após a identificação, depositados na Coleção Entomológica de Referência do Laboratório de Ecologia e Taxonomia de Artrópodes. Como resultados deste estudo registraram-se três espécies de Cerambycidae. Psapharochrus bivittis (White) (Lamiinae) foi a espécie mais representativa com 256 indivíduos amostrados, representando 92,4\% do total capturado. As espécies de Cerambycinae apresentaram baixa densidade de emergência nos galhos e troncos de $V$. divergens. Somente 12 indivíduos de Luscosmodicum beaveari Martins foram coletados (4,3\%) e nove de Neoeme bouvieri Gounelle (3,2\%) (Tabela 1).

A espécie $P$. bivittis possui registros para os Estados do Amazonas, Pará, Espírito Santo e São Paulo, e tem como plantas hospedeiras Vochysia neyratii e V. tomentosa (Monné, 2005). A espécie $L$. beaveari é originalmente descrita para o leste de Mato Grosso, na região da Serra do Roncador. Com relação a sua planta hospedeira, o catálogo de MARTins (1997) indica, de acordo com as etiquetas dos exemplares depositados no MCNZ, que os mesmos foram coletados em "galhos de cambará" no Pantanal matogrossense, além de sugerir que a espécie pode ser encontrada sob a casca dessa planta. O nome científico do "cambará" não esta está mencionado. A espécie N. bouvieri está distribuída pelo Pará (Cachimbo) e Mato Grosso (Lucas do Rio Verde, Rosário Oeste, Sinop e Vera), sem registro de planta hospedeira.

O período compreendido entre os meses de novembro/99 e fevereiro/oo foi o que apresentou maior concentração de emergência de cerambicídeos, concomitantemente ao início dos períodos de enchente e cheia na região norte do Pantanal de Mato Grosso, evidenciando, assim, sincronia entre o ciclo de vida destas espécies de Cerambycidae e o regime hídrico desta região. Esta sincronia demonstra que estas espécies emergem dos troncos e galhos caídos no solo antes que ocorra a inundação, e que as mesmas sejam carreadas ou submersas. Dessa maneira, pode-se inferir sobre a estreita associação entre os Cerambycidae, principalmente os representantes de Lamiinae, e esta espécie vegetal típica da região norte do Pantanal de Mato Grosso, mas também sobre sua adaptação ao ciclo de cheias e secas desta região.

Tabela 1. Densidade de emergência de Cerambycidae obtidos em monitoramento de galhos e troncos de Vochysia divergens Pohl (Vochysiaceae) mantidos em caixas de criação em laboratório de julho de 1999 a junho de 2000.

\begin{tabular}{|c|c|c|c|c|c|c|c|c|c|c|c|c|c|c|}
\hline \multirow[t]{2}{*}{ Táxons } & \multicolumn{6}{|c|}{1999} & \multicolumn{6}{|c|}{2000} & \multirow[t]{2}{*}{ Total } & \multirow[t]{2}{*}{$\%$} \\
\hline & Jul & Ago & Set & Out & Nov & Dez & Jan & Fev & Mar & Abr & Mai & Jun & & \\
\hline \multicolumn{15}{|c|}{ Lamiinae } \\
\hline Psapharochrus bivittis & - & - & - & 1 & - & 26 & 180 & 39 & 9 & - & 1 & - & 256 & 92,4 \\
\hline \multicolumn{15}{|c|}{ Cerambycinae } \\
\hline Luscosmodicum beaveari & - & - & - & - & 12 & - & - & - & - & - & - & - & 12 & 4,3 \\
\hline Neoeme bouvieri & - & - & - & 4 & - & 1 & - & 2 & - & - & 2 & - & 9 & 3,2 \\
\hline Total & - & - & - & 5 & 12 & 27 & 180 & 41 & 9 & - & 3 & - & 277 & 100,0 \\
\hline
\end{tabular}

\section{AGRADECIMENTOS}

Os autores agradecem ao Programa de Pós-Graduação de Ecologia e Conservação da Biodiversidade (IB-UFMT). Ao Dr. Ubirajara R. Martins - Museu de Zoologia/Universidade de São Paulo, pela identificação dos Cerambycidae.

\section{REFERÊNCIAS}

Abreu, R., B. Ronchi-Teles, M. Monné \& B. Vianez, 2009. First record of species of Cerambycidae (Coleoptera) in cardeiro (Scleronema micranthum) (Bombacaceae) in the Central Amazon. Neotropical Entomology, 38: 432-433.

Marques, M.I., J. Adis, C. Nunes-da-Cunha \& G.B. Santos, 2001. Arthropod biodiversity in the canopy of Vochysia divergens Pohl (Vochysiaceae), a forest dominant in the Brazilian Pantanal. Studies on Neotropical Fauna and Environment, 36: 205-210.

Marques, M.I., J. Adis, G.B. Santos \& L.D. Battirola., 2006. Terrestrial arthropods from the canopy in the Pantanal of
Mato Grosso, Brazil. Revista Brasileira Entomologia, 50: 257267.

Martins, U.R., 1997. Cerambycidae Sul-Americanos (Coleoptera). Taxonomia. São Paulo, Sociedade Brasileira de Entomologia, 1:1-217.

Martins, U.R. \& M.H. Galileo, 2004. Cerambycidae (Coleoptera) Coletados na Venezuela na copa de Matayba (Sapindaceae) e Vochysia (Vochysiaceae). Revista Brasileira de Entomologia, 48: 229-232.

Monné, M.A., 2005. Catalogue of the Cerambycidae (Coleoptera) of the Neotropical Region. Part II. Subfamily Lamiinae. Zootaxa, 1023: 1-760.

Nascimento, M.T. \& C. Nunes-da-Cunha, 1989. Estrutura e composição florística de um cambarazal no Pantanal de Poconé, MT. Acta Botânica Brasílica, 3: 2-23.

\section{Recebido em: 3o/o1/2013}

Aceito em: o8/06/2014

\section{Como citar este artigo:}

Marques, M.I., G.B. Santos \& L.D. Battirola, 2014. Cerambycidae (Insecta, Coleoptera) Associados à Vochysia divergens Pohl (Vochysiaceae) na Região Norte do Pantanal de Mato Grosso, Brasil. EntomoBrasilis, 7 (2): 159-160.

Acessível em: doi:10.12741/ebrasilis.v7i2.317
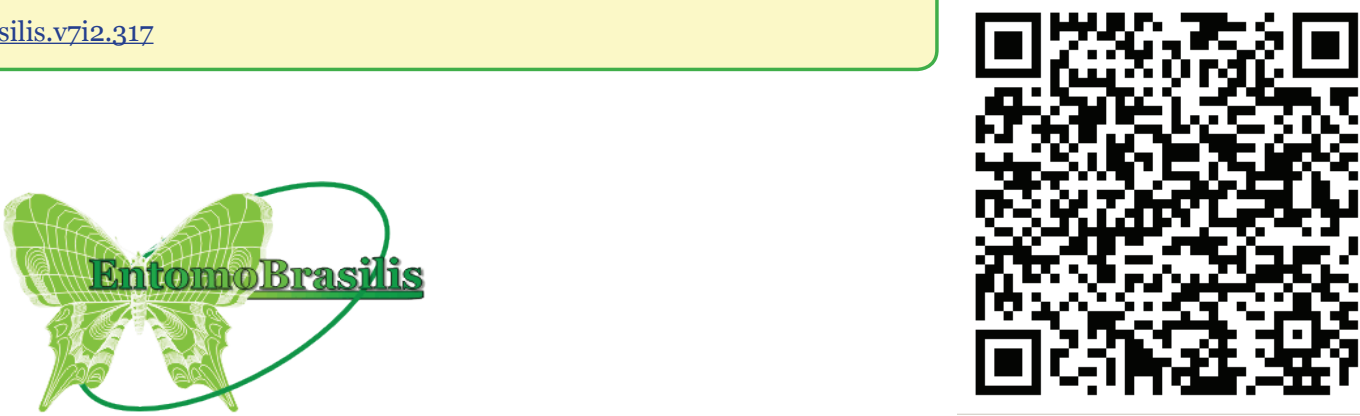